\title{
Relação proteína:carboidrato no desempenho e metabolismo de juvenis de pacamã (Lophiosilurus alexandri)
}

\author{
[Ratio protein:carbohydrate on performance and metabolism of \\ Juvenile (Lophiosilurus alexandri)] \\ R.A.C.R. Figueiredo ${ }^{1}$, R.C. Souza ${ }^{2}$, K.S. Bezerra ${ }^{3}$, D.F.B. Campeche $^{4}$, \\ R.M.L. Campos ${ }^{2}$, A.M. Souza ${ }^{2}$, J.F.B. Melo ${ }^{2 *}$
${ }^{1} 3^{a}$ Superintendência Regional da Companhia de Desenvolvimento dos Vales do São Francisco e do Parnaíba - CODEVASF - Petrolina, PE
${ }^{2}$ Universidade Federal do Vale do São Francisco - UNIVASF - Petrolina, PE
${ }^{3}$ Universidade Federal de São Carlos - PPGERN - São Carlos, SP
${ }^{4}$ EMBRAPA Semiárido - Petrolina, PE

\begin{abstract}
RESUMO
Objetivou-se neste estudo verificar o melhor nível de inclusão entre proteína e carboidrato no desempenho e algumas respostas metabólicas em juvenis de pacamã (Lophiosilurus alexandri). Testaramse quatro dietas com as relações proteína/carboidrato (PB:CHO) 1,24; 0,84; 0,51 e 0,33 durante 60 dias. Foram utilizados 240 juvenis de pacamã pesando inicialmente $1,90 \mathrm{~g}$, alimentados duas vezes ao dia (8\% da biomassa). Avaliou-se o ganho de peso total, taxa de crescimento específico, consumo de ração aparente, conversão alimentar aparente, rendimento de carcaça e gordura visceral. Glicemia, aminoácidos totais livres no plasma e glicogênio hepático também foram avaliados. A relação PB:CHO influenciou $(\mathrm{P}<0,05)$ os parâmetros de desempenho e metabolismo, exceto o glicogênio hepático. Maiores concentrações de glicose e aminoácidos totais livres no plasma foram observadas nos peixes que se alimentaram com a dieta contendo a maior relação PB:CHO $(1,24)$. Além disso, observaram-se melhores médias de ganho de peso, taxa de crescimento específico e conversão alimentar aparente. Maiores percentuais de gordura visceral e menor rendimento de carcaça foram observados nos animais submetidos à dieta composta pela menor relação $\mathrm{PB}: \mathrm{CHO}(0,33)$. Pode-se concluir que a dieta com a relação PB:CHO de 1,24 promoveu melhor desempenho e respostas metabólicas em juvenis de pacamã.
\end{abstract}

Palavras-chave: nutrição de peixes, respostas bioquímicas, bagre, pacamã

\begin{abstract}
The aim of this study was to determine the best level of inclusion between protein and carbohydrate on performance and some metabolic responses in juvenile pacamã (Lophiosilurus alexandri). We tested four diets regarding protein/carbohydrate (PB: $C H O)$ 1.24, 0.84, 0.51 and 0.33 for 60 days. The experiment was conducted with 240 juvenile pacamã initially weighing $1.90 \mathrm{~g}$, fed twice daily ( $8 \%$ of the biomass). We evaluated the total weight gain, specific growth rate, feed intake, feed conversion, carcass yield and visceral fat. Glucose, total plasma free amino acids and liver glycogen were also evaluated. The relationship PB: $\mathrm{CHO}$ influenced $(P<0.05)$ the performance and metabolism parameters except the liver glycogen. Higher concentrations of glucose and total plasma free amino acids were observed in fish that were fed the diet containing the highest ratio PB: CHO (1.24); and we also observed better mean weight gain, specific growth rate and feed conversion. A higher percentage of visceral fat and lower carcass yield were observed in animals treated with diet composed by the lower ratio PB: CHO (0.33). We can conclude that a diet with a ratio $P B$ : $C H O$ of 1.24, promotes better performance and metabolic responses in juvenile pacamã.
\end{abstract}

Keywords: fish nutrition, biochemical responses, catfish, pacamã

Recebido em 4 de fevereiro de 2013

Aceito em 16 de dezembro de 2013

*Autor para correspondência (corresponding author)

E-mail: melojfb@yahoo.com.br 


\section{INTRODUÇÃO}

O alto custo com alimentação é um dos fatores que causam impacto na produção intensiva de peixes. A proteína é um dos ingredientes que mais oneram o custo das dietas na piscicultura, e preferencialmente são utilizadas como fonte energética. Nos peixes, as proteínas são bem digeridas e absorvidas na forma de aminoácidos; entretanto, quando há muita disponibilidade, estes são absorvidos pelas células e sofrem desaminação, e os esqueletos de carbono usados para síntese energética (Jobling, 1994). A redução do catabolismo proteico para fins energéticos pode ser obtida através da utilização de níveis adequados de fontes de energia não proteica, como os carboidratos, possibilitando que a proteína seja destinada à formação de tecido muscular (Hisano e Portz, 2007).

As concentrações de carboidratos presentes nas dietas são variáveis em função da espécie, do hábito alimentar, da capacidade de digestão e devido às diferenças anatômicas do trato gastrointestinal (Aderolu et al., 2009). Em relação às proteínas, as pesquisas apontam para o conhecimento da quantidade mínima de que o organismo necessita para retribuir com melhor eficiência na produção (Hammer et al., 2006; Heflin et al., 2012). Uma vez que o carboidrato é o nutriente energético de menor custo na elaboração das rações, faz-se necessária a determinação das proporções ideais desses constituintes na formulação das dietas para a maximização da produção e obtenção de lucro no cultivo intensivo de peixes (Aderolu et al., 2009), visando minimizar o uso de proteína para fins energéticos, principalmente em espécies carnívoras como o L. alexandri.

O bagre denominado pacamã é considerado endêmico do Rio São Francisco, teve a sua importância enaltecida por vários autores pelo seu alto valor de mercado, ausência de espinhos intramusculares e pela qualidade da sua carne (Tenório, 2003; Pedreira et al., 2008). Aliando suas qualidades organolépticas a outras características, tais como: facilidade na propagação artificial, aceitação de alimentos inertes, rusticidade, e possuir características zootécnicas que favorecem o rendimento de filé, tornam a espécie com características desejáveis para o cultivo comercial (Cardoso, 1992; Rizzo e Godinho, 2003; Sato et al., 2003).
Estudos sobre a criação da espécie, principalmente sobre a nutrição, são muito escassos, resumindo-se a alguns trabalhos com larvicultura. Por ser uma espécie de importância para a piscicultura na região semiárida brasileira, é necessário avaliar parâmetros nutricionais e metabólicos para o desenvolvimento de pacote tecnológico na produção dessa espécie.

Portanto, objetivou-se neste estudo determinar a proporção ideal entre proteína e carboidrato no desempenho e em algumas respostas metabólicas do L. alexandri.

\section{MATERIAL E MÉTODOS}

O experimento foi realizado no Laboratório de Aquicultura da Universidade Federal do Vale do São Francisco. Foram testadas quatro dietas experimentais com diferentes relações proteína/carboidrato (PB: $\mathrm{CH}$ ), nas razões de 1,$24 ; 0,84 ; 0,51$ e 0,33 (Tab. 1).

Para elaboração das rações, inicialmente foram adquiridas as matérias-primas e trituradas para obtenção de menor granulometria possível. Após pesagem e homogeneização dos ingredientes, as dietas foram confeccionadas, com adição de $20 \%$ de água a $45^{\circ} \mathrm{C}$, peletizadas em moinho de carne e desidratadas em estufa de ventilação forçada a $55^{\circ} \mathrm{C}$, durante um período de $24 \mathrm{~h}$ e armazenadas em freezer.

Os peixes foram adquiridos na Estação de Piscicultura de Bebedouro da CODEVASF, a partir de reprodução natural. Os peixes foram treinados à alimentação com ração, sendo alimentados nos primeiros 30 dias com náuplios de branconetas, e posteriormente ao treinamento com a inclusão da ração por um período de 15 dias. Antes do experimento, os peixes foram adaptados por 7 dias, nos quais receberam ração comercial com $38 \%$ de PB. Em cada unidade experimental (caixas) de $500 \mathrm{~L}$, foram estocados 20 peixes com peso médio inicial de $10,0 \mathrm{~g}$, distribuídos em um sistema fechado de recirculação de água com biofiltro. Diariamente nas unidades experimentais, foram monitorados a temperatura da água, $\mathrm{pH}$ e oxigênio dissolvido. A temperatura média da água e o $\mathrm{pH}$ nas caixas foram: $25,6 \pm 0,77^{\circ} \mathrm{C}$ e $27,5 \pm 0,86$ e $\mathrm{pH} 7,39 \pm 0,36$ e 7,4 $\pm 0,38$ para manhã e tarde, respectivamente. $\mathrm{O}$ oxigênio dissolvido médio foi de $5,2 \pm 0,18 \mathrm{mg} . \mathrm{L}^{-1}$ e amônia total média de 
0,012mg. $\mathrm{L}^{-}$durante o período experimental.

Cada unidade experimental era sinfonada para limpeza e reposição da água.

Tabela 1. Formulação, composição percentual e composição bromatológica das dietas utilizadas na alimentação de alevinos de pacamã (L. alexandri)

\begin{tabular}{|c|c|c|c|c|}
\hline \multirow{2}{*}{ Ingredientes } & \multicolumn{4}{|c|}{ Relações PB:CHO } \\
\hline & 1,24 & 0,84 & 0,51 & 0,33 \\
\hline Farinha de peixe & 64,1 & 51,6 & 39,1 & 26,6 \\
\hline Farelo de soja & 10 & 7,5 & 5 & 2,5 \\
\hline Farinha de milho & 15 & 30 & 45 & 60 \\
\hline Óleo de soja & 8 & 8 & 8 & 8 \\
\hline Premix mineral e vitamínico ${ }^{1}$ & 2 & 2 & 2 & 2 \\
\hline Vit $C^{2}$ & 0,05 & 0,05 & 0,05 & 0,05 \\
\hline $\mathrm{BHT}^{3}$ & 0,01 & 0,01 & 0,01 & 0,01 \\
\hline Fosfato bicálcico & 0,84 & 0,84 & 0,84 & 0,84 \\
\hline \multirow[t]{2}{*}{ Total } & 100 & 100 & 100 & 100 \\
\hline & \multicolumn{3}{|c|}{ Composição bromatológica } & \\
\hline $\mathrm{PB}(\%)^{4}$ & 39,52 & 34,06 & 27,03 & 20,84 \\
\hline $\operatorname{ENN}(\%)^{5}$ & 31,90 & 40,64 & 52,55 & 62,83 \\
\hline $\mathrm{EB}(\mathrm{Kcal} / \mathrm{kg})^{6}$ & 5263 & 5279 & 5190 & 5139 \\
\hline $\mathrm{EE}(\%)^{7}$ & 9,81 & 9,05 & 8,88 & 8,02 \\
\hline $\mathrm{FB}(\%)^{8}$ & 2,95 & 2,90 & 2,98 & 3,04 \\
\hline $\operatorname{MM}(\%)^{9}$ & 18,82 & 16,35 & 12,56 & 09,27 \\
\hline $\operatorname{MO}(\%)^{10}$ & 81,18 & 83,65 & 87,44 & 90,73 \\
\hline $\operatorname{MS}(\%)^{11}$ & 94,21 & 93,64 & 93,19 & 90,75 \\
\hline
\end{tabular}

1: Premix min. e vit. (Supremais, Campinas-SP): Composição por quilo de produto: vit. A = 1.200.000 UI; vit. D3 = $200.000 \mathrm{UI}$; vit. $\mathrm{E}=12.000 \mathrm{mg}$; vit. $\mathrm{K} 3=2.400 \mathrm{mg}$; vit. $\mathrm{B} 1=4.800 \mathrm{mg}$; vit. $\mathrm{B} 2=4.800 \mathrm{mg}$; vit. $\mathrm{B} 6=4.000 \mathrm{mg}$; vit. $\mathrm{B} 12=4.800 \mu \mathrm{g}$; ác. fólico $=1.200 \mathrm{mg}$; pantotenato de cálcio $=12.000 \mathrm{mg}$; vit. $\mathrm{C}=48.000 \mathrm{mg}$; biotina $=48 \mathrm{mg}$; colina $=65.000 \mathrm{mg}$; ácido nicotínico $=24.000 \mathrm{mg} ; \mathrm{Fe}=10.000 \mathrm{mg} ; \mathrm{Cu}=600 \mathrm{mg} ; \mathrm{Mn}=4.000 \mathrm{mg} ; \mathrm{Zn}=6.000 \mathrm{mg} ; \mathrm{I}=20 \mathrm{mg}$; Co $=2 \mathrm{mg}$ e $\mathrm{Se}=20 \mathrm{mg}$; 2: Vit. C (Basf, São Paulo-SP): sal cálcica 2-monofosfato de ácido ascórbico, $42 \%$ de princípio ativo; 3: Butil-Hidroxi-tolueno. 4: PB - Proteína bruta; 5: ENN- Extrativo não nitrogenado; 6: EB - Energia bruta; 7: EE - Extrato etéreo; 8: FB - Fibra bruta; 9: MM - Matéria mineral; 10: MO - Matéria orgânica; 11: MS Matéria seca.

A cada 15 dias foram realizadas biometrias (peso e comprimento total) para o cálculo das variáveis de desempenho e correção da ração ofertada. Avaliaram-se o peso médio inicial (PMI), ganho médio de peso total (GMPT), ganho médio diário (GMD), consumo médio de ração aparente (CMRA), conversão alimentar aparente (CAA), taxa de crescimento específico (TCE), gordura visceral $(\mathrm{GV})$ e rendimento médio de carcaça (RC). Além disso, também foram avaliadas as respostas metabólicas glicemia plasmática, aminoácidos totais livres no plasma e glicogênio hepático conforme metodologias descritas em Melo (2004).

Os dados foram submetidos à análise de variância com nível de significância de 5\%, com médias comparadas pelo teste Tukey. Em caso de diferença significativa, foi realizada análise de regressão. O delineamento experimental aplicado foi inteiramente ao acaso com quatro tratamentos e três repetições. Os resultados foram analisados pelos programas Statistical Analysis System (SAS).

\section{RESULTADOS E DISCUSSÃO}

Os dados do desempenho zootécnico dos juvenis de pacamã estão descritos na Tabela 2 . Verificou-se que a relação $\mathrm{PB}: \mathrm{CHO}$ influenciou significativamente o peso dos animais. A relação PB:CHO de 1,24 apresentou melhores resultados entre os tratamentos testados, a qual diferiu estatisticamente. Observou-se efeito linear à medida que houve redução nos teores de proteína e aumento nos carboidratos na ração (Fig. 1A 1B e 1C), o que demonstra que o pacamã não tolera altos níveis de carboidratos na dieta e, portanto, estes dois nutrientes (proteína e carboidratos) devem estar balanceados para que o animal obtenha maiores índices produtivos no PMF, GPMT e GMD. 
As concentrações de proteína e carboidrato têm sido objeto de pesquisa na nutrição de peixes para melhorar o equilíbrio das rações, visando maior desempenho e redução de custos. Nesses estudos existem muitas variações em relação a esses nutrientes. Em trabalho realizado por Fernández et al. (2007) com o carnívoro Sparus aurata, estes observaram melhor desempenho dos animais quando utilizaram dieta contendo $53,9 \%$ de proteína e 19,6\% de carboidrato, numa relação $\mathrm{PB}: \mathrm{CHO}$ de 2,75 , sendo superior à relação testada neste trabalho para $0 \quad L$. alexandri.

A influência da quantidade de proteína e carboidrato nas dietas sobre o desempenho tem algumas explicações. Peragón et al. (1999) relataram que a redução no crescimento de Oncorhynchus mykiss ocorreu pela relação entre carboidratos e proteína na alimentação, a qual induz ao uso de aminoácidos obtidos da digestão e da degradação muscular para fins gliconeogênicos. Em estudo realizado com Salmo trutta alimentado com diferentes níveis de proteína e carboidrato, observou-se que o desempenho foi superior quando a dieta continha $45,2 \%$ de proteína e $27,8 \%$ de carboidrato (Viaplana-Marín et al., 2006), ao passo que, neste trabalho, o melhor desempenho foi com $39,52 \%$ de proteína e 31,90\% de carboidrato. Já com híbrido de Surubim x Cachara, não foi verificada influência no desempenho com níveis de proteína até 36\% (Sánchez et al., 2009).

Tabela 2. Valores médios dos índices de desempenho e respostas metabólicas plasmáticas em juvenis de pacamã alimentados com diferentes relações PB:CHO por um período de 60 dias

\begin{tabular}{|c|c|c|c|c|}
\hline \multirow{2}{*}{ Variáveis de desempenho } & \multicolumn{4}{|c|}{ Relação PB:CHO } \\
\hline & 1,24 & 0,84 & 0,51 & 0,33 \\
\hline $\operatorname{PMI}(\mathrm{g})^{1}$ & $1,93 a \pm 0,18$ & $1,88 \mathrm{a} \pm 0,13$ & $1,93 \mathrm{a} \pm 0,14$ & $1,88 \mathrm{a} \pm 0,08$ \\
\hline $\operatorname{PMF}(g)^{2}$ & $21,90 \mathrm{a} \pm 2,93$ & $13,14 b \pm 0,40$ & $7,78 \mathrm{c} \pm 1,60$ & $4,94 c \pm 0,32$ \\
\hline $\operatorname{GPMT}(\mathrm{g})^{3}$ & $19,98 \mathrm{a} \pm 3,10$ & $11,26 b \pm 0,29$ & $5,85 \mathrm{c} \pm 1,67$ & $3,06 c \pm 0,36$ \\
\hline GMD (g/dia) $)^{4}$ & $0,33 \mathrm{a} \pm 0,05$ & $0,18 b \pm 0,00$ & $0,09 c \pm 0,03$ & $0,05 \mathrm{c} \pm 0,01$ \\
\hline $\operatorname{CMRA}(\mathrm{g})^{5}$ & $21,48 \mathrm{a} \pm 0,83$ & $19,30 \mathrm{a} \pm 0,65$ & $14,61 b \pm 1,50$ & $12,40 b \pm 1,15$ \\
\hline $\operatorname{TCE}(\%)^{6}$ & $4,05 \mathrm{a} \pm 0,38$ & $3,24 b \pm 0,07$ & $2,30 \mathrm{c} \pm 0,43$ & $1,61 \mathrm{~d} \pm 0,16$ \\
\hline $\mathrm{CAA}^{7}$ & $1,09 \mathrm{~b} \pm 0,17$ & $1,71 \mathrm{~b} \pm 0,04$ & $2,65 \mathrm{ab} \pm 0,88$ & $4,11 \mathrm{a} \pm 0,82$ \\
\hline $\mathrm{GV}(\%)^{8}$ & $1,12 b \pm 0,65$ & $1,24 b \pm 0,39$ & $1,39 b \pm 0,89$ & $3,02 \mathrm{a} \pm 1,28$ \\
\hline $\mathrm{RC}(\%)^{9}$ & $82,01 \mathrm{a} \pm 4,09$ & $81,63 \mathrm{ab} \pm 4,10$ & $79,20 \mathrm{ab} \pm 3,74$ & $77,42 b \pm 2,75$ \\
\hline \multicolumn{5}{|l|}{ Variáveis Metabólicas } \\
\hline $\mathrm{GL}^{10} \mathrm{mg} / \mathrm{dL}$ & $51,30 \mathrm{a} \pm 16,43$ & $28,60 \mathrm{~b} \pm 12,05$ & $29,50 \mathrm{~b} \pm 7,45$ & $25,10 b \pm 6,23$ \\
\hline $\mathrm{GH}^{11} \mu \mathrm{mol} / \mathrm{g}$ tecido & $97,39 a \pm 15,61$ & $125,02 \mathrm{a} \pm 32,44$ & $123,98 \mathrm{a} \pm 34,25$ & $128,06 \mathrm{a} \pm 30,11$ \\
\hline $\mathrm{AAT}^{12}$ nmoles/ml plasma & $24,33 a \pm 3,92$ & $23,70 \mathrm{ab} \pm 4,70$ & $18,72 b \pm 3,50$ & $7,50 \mathrm{c} \pm 2,54$ \\
\hline
\end{tabular}

Médias seguidas por letra distinta diferem entre si pelo teste Tukey a $5 \%$.

1- PMI: Peso médio inicial; 2- PMF: Peso médio final; 3- Ganho de peso médio total; 4- GMD: Ganho médio diário; 5- CMRA: Consumo médio de ração aparente; 6- TCE: Taxa de crescimento específico 7- CAA: Conversão alimentar aparente; 8- GV: Gordura visceral; 9- RC: Rendimento de carcaça; 10- GL: Glicemia; 11- GH: Glicogênio hepático; 12- AAT: Aminoácidos totais livres.

Alguns trabalhos têm demonstrado que o desequilíbrio da proteína e carboidrato afeta o desempenho dos animais devido às alterações metabólicas ocorridas. A proporção de proteína anabolizada e catabolizada depende do requerimento proteico do peixe, o conteúdo proteico da dieta, a proporção dos vários aminoácidos entre si, a energia requerida e a quantidade de energia disponível de outras fontes, assim como gordura e carboidratos (Hepher, 1988). Quando ocorre a falta de energia provinda de carboidratos, o catabolismo de 
aminoácidos para produzir energia supre essa demanda. Assim, dietas com níveis adequados de proteínas, mas com nível inadequado de energia, poderão ser insuficientes para permitir o anabolismo e, consequentemente, será utilizada a proteína para energia. Esse fato foi observado no crescimento reduzido das trutas quando receberam dietas ricas em glicídios, devido a uma redução da digestibilidade e como consequência de alterações metabólicas que provocaram outras desordens graves (Phillips et al., 1948).

As proteínas não são idênticas em seus valores nutricionais. $\mathrm{O}$ valor nutricional de uma fonte de proteína é em função da digestibilidade e da composição em aminoácidos. Existem alguns ingredientes proteicos que contêm altos níveis de proteína bruta, mas que contêm uma grande proporção de nitrogênio não-proteico (Cho, 1990). Dessa forma, o reflexo da variação da quantidade de proteína e carboidrato, além de afetar o desempenho, tem como resposta primária as vias metabólicas.

Para dietas com alto conteúdo proteico e baixo de carboidrato, as atividades das enzimas glicolíticas estão deprimidas e as gluconeogênicas, aumentadas, ocorrendo o inverso quando o nível de glicídios na dieta está aumentado (Higuera et al., 1977). Essa variação das vias metabólicas implica diretamente no aproveitamento dos nutrientes e consequentemente no desempenho. Neste estudo, observou-se o efeito desses nutrientes no peso dos animais.

Para a TCE, verificou-se que as respostas foram semelhantes às variáveis de desempenho. A maior média de crescimento foi para a relação PB:CHO de 1,24, a qual apresentou efeito linear (Fig. 1E). Ao testarem diferentes relações PB:CHO na dieta da dourada Sparus aurata, Fernández et al. (2007) não observaram melhoras na TCE com o aumento da relação, resultados distintos aos encontrados neste trabalho. O mesmo ocorreu com Leiarius marmoratus alimentados com níveis de proteína de 28,32 e $36 \%$ e não apresentaram variações no TCE (Sánchez et al., 2009). Souza et al. (2011) avaliaram o desempenho zootécnico de juvenis de robalo-peva com dietas contendo diferentes níveis de proteína, verificaram resposta linear para a taxa de crescimento específico com melhor resposta no nível de 48,99\% de proteína, valor bem acima dos encontrados neste trabalho, que foi de $39,52 \%$.

O consumo total de ração aparente (CTRA) foi influenciado pelas relações $\mathrm{PB}: \mathrm{CHO}$ imposta aos animais. Verificou-se aumento longitudinal no consumo nas dietas que continham maiores quantidades de carboidratos (Fig. 1D). Os menores consumos de ração ocorreram nos grupos tratados com as relações $\mathrm{PB}: \mathrm{CHO}$ de 1,24 e 0,84. De acordo com Lovell (1988), o consumo é regulado pela concentração de energia na dieta. Os dados de (CMRA) corroboram os encontrados por Aksnes (1995), que observou menor consumo de ração conforme aumentou os níveis de carboidratos na dieta do Salmão do Atlântico. Semelhantemente, Sampaio et al. (2000), em estudo com o tucunaré, obtiveram os mesmos resultados, com maiores consumos nos maiores níveis de proteína. O menor CTRA nas rações com maiores teores de carboidratos provavelmente pode ter ocorrido devido à maior disponibilidade energética deste ingrediente, podendo ter causado a saciedade nos peixes e consequentemente um menor consumo.

$\mathrm{O}$ rendimento da carcaça e gordura visceral nas relações 1,$24 ; 0,84$ e 0,51 não apresentaram diferença significativa (Tab. 2). O rendimento teve efeito sigmoide na equação (Fig. $1 \mathrm{H}$ ), pois o pior rendimento foi na ração com maior concentração de carboidrato, relação PB:CHO de 0,33. Diferentemente deste trabalho, Reidel (2007) não observou diferenças significativas com o aumento dos níveis de proteína para esse parâmetro. Se o teor de energia de uma dieta não for suficiente, ou se a proteína for de baixa qualidade, ela será desaminada para servir como fonte de energia para o metabolismo. Dessa forma, baixa relação energia:proteína pode reduzir a taxa de crescimento devido ao aumento da demanda metabólica para excreção de nitrogênio. Segundo Steffens (1989), cada 1,0 grama de proteína na carcaça equivale a $5,7 \mathrm{kcal}$ de energia, e cada $1,0 \mathrm{~g}$ de gordura, a 9,5kcal de energia; essas relações entre os nutrientes produzem variações no rendimento da carcaça dos peixes. Excesso de energia na ração pode causar deposição excessiva de gordura nos peixes e reduzir consumo de alimento, inibindo a utilização de outros nutrientes (Cho, 1990). 
A conversão alimentar e a gordura visceral aumentaram seus índices à medida que se reduziu a relação $\mathrm{PB}: \mathrm{CHO}$ (Figura $1 \mathrm{~F}$ e $2 \mathrm{G}$ ). Portanto, essas variáveis foram dependentes da relação PB:CHO. A gordura visceral é um fator que afeta diretamente o rendimento de carcaça, aumentando o volume nas vísceras.

$\mathrm{Na}$ relação de 1,24, a conversão alimentar aparente foi mais eficiente devido a um melhor aproveitamento proteico. A conversão alimentar relaciona o consumo de ração e o ganho de peso. Assim, quanto maior a conversão alimentar, maior o gasto com ração, entretanto ela varia dependendo do sistema de produção. $\mathrm{Na}$ alimentação do L. alexandri, o requerimento de proteína é alta, como demonstra o experimento, fato esse justificado pelo seu hábito alimentar carnívoro. Teimei et al. (1969) obtiveram em catfish conversão alimentar acima de 2:1. Veras et al. (2010) verificaram em alevinos de traíra redução na conversão alimentar em relação ao aumento de proteína de 35 para $47 \%$.

A melhor conversão alimentar foi de $1,09 \pm 0,17$, fato esse relevante diante do alto custo com ração para carnívoros a partir de seu conteúdo proteico elevado. A diminuição na relação PB:CHO causou aumento da conversão alimentar que, no caso do pacamã, chegou a $4,11 \pm 0,82$, provavelmente devido ao alto teor de carboidratos (Figura 1E).

Os níveis de gordura visceral foram significativamente maiores $(\mathrm{P}<0,05)$ na dieta contendo a menor relação $\mathrm{PB}: \mathrm{CHO}(0,33)$. Embora as concentrações de energia das dietas estivessem próximas, provavelmente a maior concentração de carboidrato não foi aproveitada pelo pacamã. Hutchins et al. (1998) observaram aumento de gordura visceral em "sunshine bass" em função do aumento de carboidratos na dieta, entretanto não observaram efeito no glicogênio hepático, conforme observado no presente estudo. Melo (2004) afirma que as concentrações de glicogênio hepático nos peixes são influenciadas pela alimentação e também, no entanto, não observou diferenças significativas para essa variável em jundiás alimentados com diversos teores de proteína na dieta. Afirma ainda que esse fato provavelmente esteve relacionado a processos gliconeogênicos a partir de aminoácidos. O glicogênio hepático não foi influenciado pelas dietas testadas (Tab. 2).

Os valores médios das variáveis metabólicas plasmáticas, glicose e aminoácidos totais, foram alterados pelas relações PC:CHO (Tab. 2). As maiores concentrações na glicemia foram observadas nos animais que receberam as maiores relações PB:CHO (Fig. 2I). A glicose plasmática é variável entre as espécies, nos diferentes estágios da vida, bem como regimes alimentares. Peixes de hábito alimentar carnívoro podem regular a glicemia por meio da gliconeogênese (Hemre et al., 2002). Em dietas contendo altos teores de proteína e baixos níveis de carboidratos, a síntese de glicose ocorre a partir dos esqueletos de carbono oriundos dos aminoácidos.

Os aminoácidos no plasma foram significativamente maiores $(\mathrm{P}<0,05)$ nos animais submetidos às dietas contendo as maiores relações $\mathrm{PB}$ :CHO (1,24 e 0,84). O efeito foi gradativo e longitudinal das menores relações para as maiores PB:CHO (Fig. 2J). Resultados semelhantes foram observados por Melo (2004) em jundiás alimentados com os maiores teores de proteína na dieta. $\mathrm{O}$ aumento da concentração de aminoácidos no plasma pode indicar gliconeogênese a partir dos elevados níveis de proteína em relação ao carboidrato da dieta. 

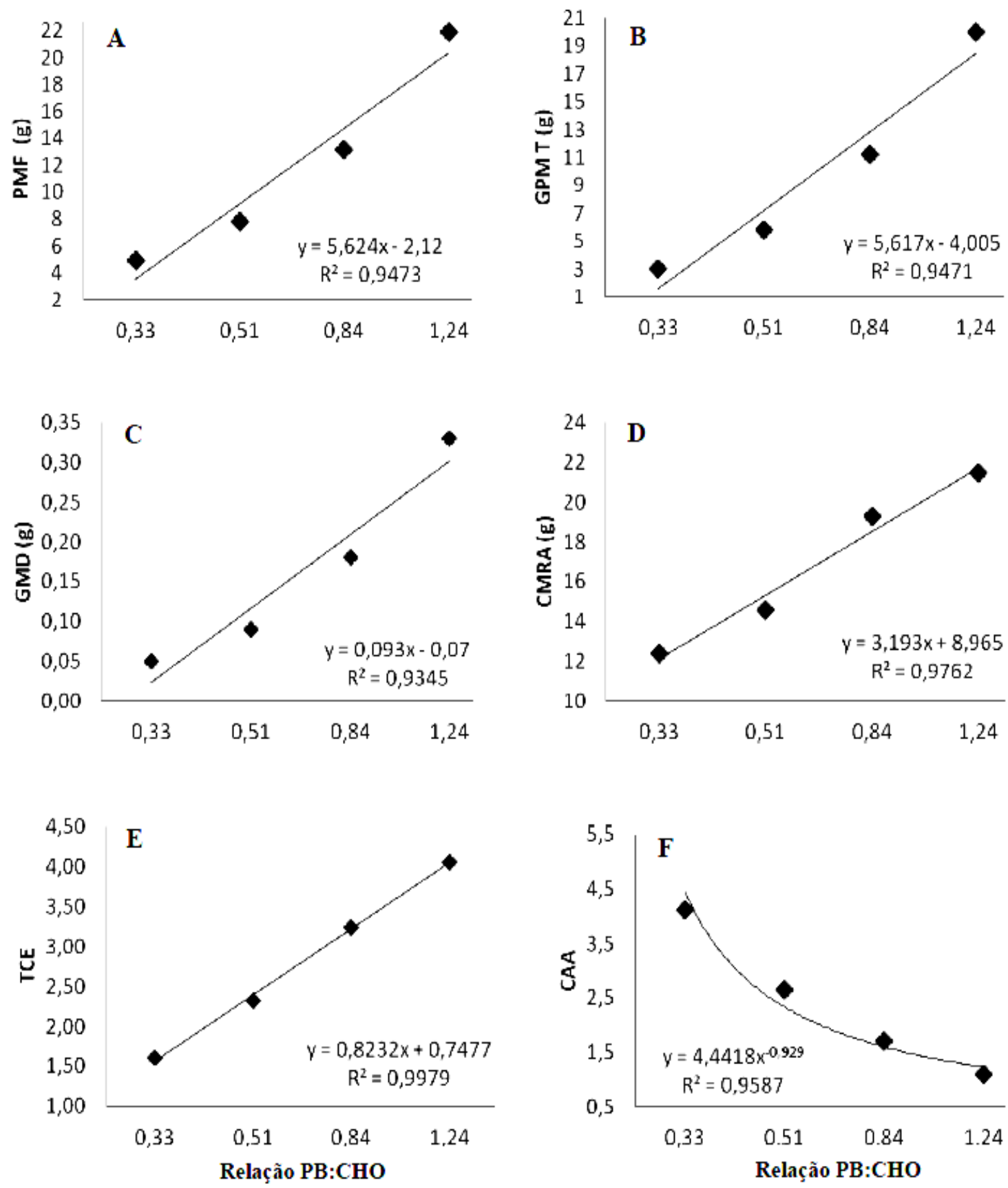

Figura 1. Representação gráfica das variáveis: Peso médio final - PMF (A); Ganho de peso médio total GPMT (B); GMD: Ganho médio diário - GMD (C); Consumo médio de ração aparente - CMRA (D); Taxa de crescimento específico - TCE (E); Conversão alimentar aparente - CCA (F). 

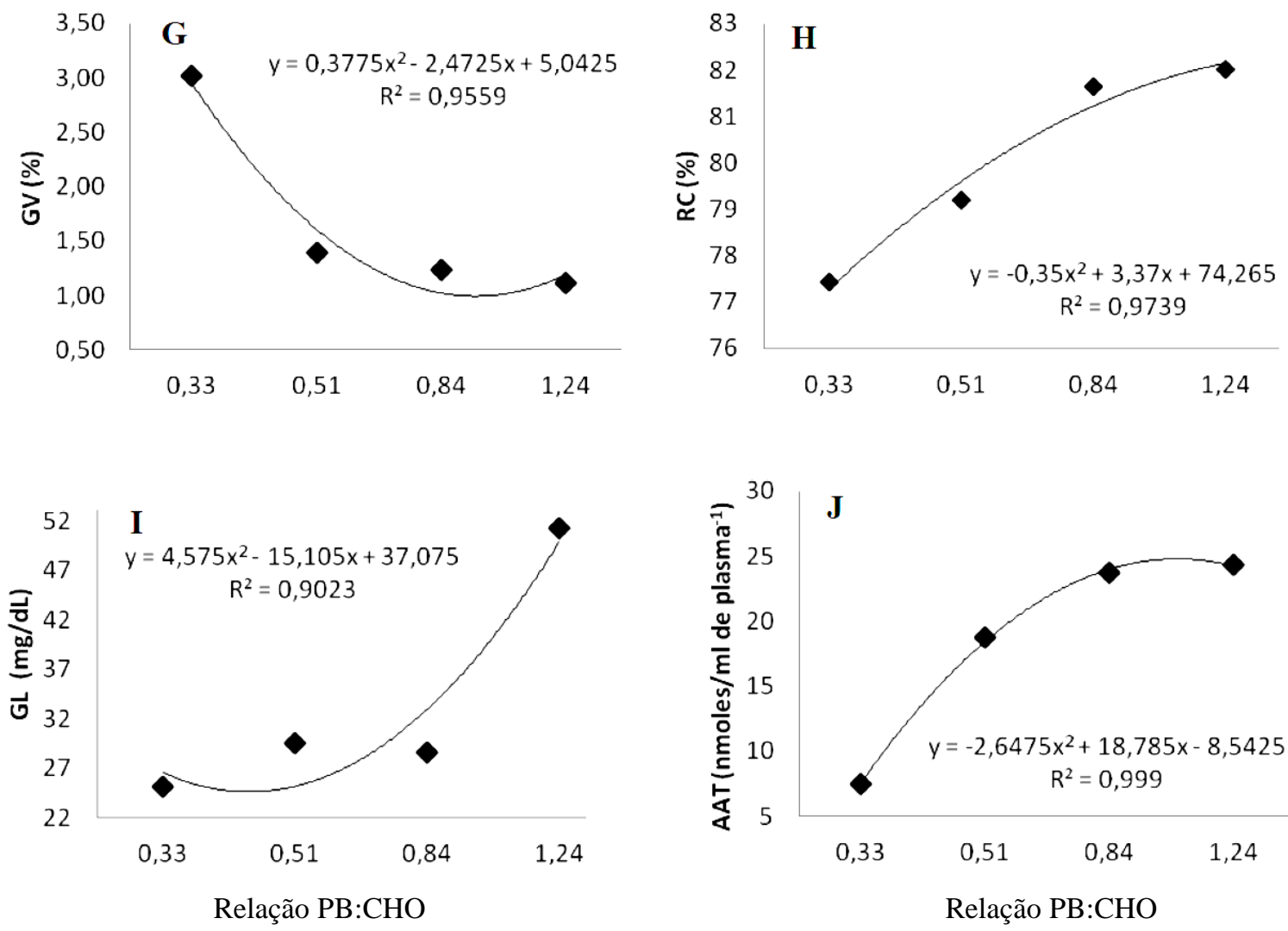

Figura 2. Representação gráfica das variáveis: Gordura visceral - GV (G); Rendimento de carcaça - RC (H); Glicemia - GL (I); Aminoácidos totais livres - AAT (J).

\section{CONCLUSÃO}

Conclui-se que a dieta contendo a relação PB:CHO de 1,24 é eficiente para o bom desempenho de juvenis de pacamã. Recomendase a inclusão de $15 \%$ de fonte de carboidrato e $40 \%$ de proteína na dieta para o pacamã. As concentrações de proteína e carboidrato testadas mantêm as reservas de glicogênio hepático e da glicemia. As concentrações de aminoácidos livres no plasma respondem às variações de $\mathrm{PB}: \mathrm{CHO}$ para manter o processo de crescimento no pacamã.

\section{REFERÊNCIAS}

ADEROLU, A.Z.; LAWAL, M.O.; OLADIPUPO, M.O. Processed Cocoyam Tuber as Carbohydrate Source in the Diet of Juvenile African Catfish (Clarias Gariepinus). Eur. J. Scient. Res., v.35, p.453-460, 2009.
AKSNES, A. Growth, feed efficiency and slaughter quality of salmon, Salmo salar L., given feeds with different ratios of carbohydrate and protein. Aquaculture Nutrit., v.1, p.241-248, 1995.

CARDOSO, L.C. Toxidez da Amônia não ionizada e seu efeito sobre a pele e brânquias de Lophiosilurus alexandri Steidachner, 1876; Prochilodus marggravii (Walbaum, 1792); Leporinus elongatus Valenciennes, 1849; (Pisces, Teleostei). 1992. 122f. (Dissertação) Mestrado em Aquicultura - Universidade Federal de Santa Catarina, Florianópolis, SC, 1992.

CHO, C.Y. Fish Nutrition, Feeds, and Feeding: With Special Emphasis on Salmonid Aquaculture. Food Reviews Intern., v.6, p.333357, 1990. 
FERNÁNDEZ, F.; MIQUEL, A.G.; CÓRDOBA, M. et al. Effects of diets with distinct protein-tocarbohydrate ratios on nutrient digestibility, growth performance, body composition and liver intermediary enzyme activites in gilthead sea bream (Sparus aurata, L.) fingerlings. J. of Experimental Marine Biol. and Ecol., v.347, p.110, 2007.

HAMMER, H.S.; HAMMER, B.W.; WATTS, S.A. et al. The effect of dietary protein and carbohydrate concentration on the biochemical composition and gametogenic condition of the sea urchin Lytechinus variegatus. J. Exp. Marine Biol. and Ecol., v.334, p.109-121, 2006.

HEFLIN, L.E.; GIBBS, V.K.; POWELL, M.L. et al. Effect of dietary protein and carbohydrate levels on weight gain and gonad production in the sea urchin Lytechinus variegates. Aquaculture, v.358-359, p.253-261, 2012.

HEMRE, G.I.; MOMMSEN, T.P.; KROGDAHL, A. Carbohydrates in fish nutrition: effects on growth, glucose metabolism and hepatic enzymes. Aquacult. Nutrition, v.8, p.175-194, 2002.

HEPHER, B. Energy pathways. Nutrition of Pond Fish. In: HEPHER, B. Requirement for protein. Cambridge: Cambridge University Press (ed.), 1988. 64-101p.

HIGUERA, M. De La.; MURILO, A.V.G.; ZAMORA, S. The influence of high dietery fat levels on protein utilization by trout (Salmo gardneri). Comp. Biochem. Physio.,v.56, p.3741, 1977.

HISANO, H.; PORTZ, L. Redução de custos de rações para tilápia: a importância da proteína. Bahia. Agric., v.8, p.42-45, 2007.

HUTCHINS, C.G.; RAWLES, S.D.; GATLIN, D.M.III. Effects of dietary carbohydrate kind and level on growth, body composition and glycemic response of juvenile sunshine bass (Morone chrysops 우 X M. saxatilis ठ). Aquaculture., v.161, p.187-199, 1998.

JOBLING, M. Fish bioenergetics. London: Chapman \& Hall. 1994. 309p.

LOVELL, R.T. Nutrition and feeding of fish. Boston: Kluwer Academic Press, 1998. 267p.
MELO, J.F.B. Digestão e metabolismo de jundiá (Rhamdia quelen) submetido a diferentes regimes alimentares, 2004. 80f. Tese (Doutorado em Ciências Fisiológicas) Universidade Federal de São Carlos. São Carlos, SP.

PEDREIRA, M.M.; SANTOS, J.C.E; SAMPAIO, E.V. et al. Efeito do tamanho da presa e do acréscimo de ração na larvicultura de pacamã. Rev. Bras. de Zootec., v.37, p.1144-1150, 2008.

PERAGÓN, J.; BARROSO, J.B.; GARCIASALGUERO, L. et al. Carbohydrates affect protein-turnover rates, growth, and nucleic acid content in the white muscle of rainbow trout (Oncorhynchus mykiss). Aquaculture., v.179, p.425-437, 1999.

PHILLIPS, A.M.; TUNISON, A.V.; BROCKWAY, D.R. The utilization of carbohydrates by trut. Fish. Res . Bull., v.11, p.1-44, 1948.

REIDEL, A. Níveis de energia e proteína na alimentação do jundiá (Rhamdia quelen) criados em tanques-rede. 2007. 85p. Tese (Doutorado em Aquicultura), Universidade Estadual Paulista - Centro de Aquicultura da UNESP CAUNESP. Jaboticabal, SP, 2007.

RIZZO, E.; GODINHO, H.P. Superfície de ovos de peixes Characiformes e Siluriformes. In: H.P. GODINHO E A.L. GODINHO (org.). Águas, peixes e pescadores do São Francisco das Minas Gerais. Belo Horizonte: PUC Minas, 2003. 468p.

SAMPAIO, A.M.B.M.; KUBITZA, F.; CYRINO, J.E.P. Relação proteína: energia na nutrição do tucunaré. Scientia Agric., v.52, p.213-219, 2000.

SÁNCHEZ, J.A.M.; MOYETONES, F.; CERDÁ, M.J. Influencia del contenido proteico en el crecimiento de alevines de bagre yaque, Leiarius marmoratus, alimentados con concentrados comerciales. Zootecnia Tropic., v.27, p.187-194, 2009.

STATISCAL analisys system - SAS - Versão 6.08. Institute, SAS/STAT. User's guide: statistic. 4.ed. North Caroline: Cary, 1996.

SATO, Y.; FENERICH-VERANI, N.; NUÑER, A.P.O. et al. Padrões reprodutivos de peixes da bacia do São Francisco. In: H.P. GODINHO E A.L. GODINHO (org.). Águas, peixes e pescadores do São Francisco das Minas Gerais. Belo Horizonte: PUC Minas, 2003. 468p. 
SOUZA, J.H.; FRACALOSSI, D.M.; GARCIA, A.S. et al. Desempenho zootécnico e econômico de juvenis de robalo peva alimentados com dietas contendo diferentes concentrações proteicas. Pesq. Agropec. Bras., v.46, p.190-195, 2011.

STEFFENS, W. Principles of fish nutrition. Chichester, England, UK: Ellis Harwood Ltda, 1989. p.184-208.

TEIMEI, O.W; DEYOE, C.W; LIPPER, R. Influence of photoperiod on growth of fed channel cat - fish (Ictalurus punctatus) in early spring and iate fall. Trans. Kansas Academic Sci., v.72, p.519-522, 1969.
TENÓRIO, R.A. Aspectos da biologia reprodutiva do niquim Lophiosilurus alexandri Steindachner, 1876 (Actinopterygii, Pimelodidae) e crescimento da progênie em diferentes condições ambientais. 2003. 73f. Dissertação (Mestrado em Recursos Pesqueiros e Aquicultura), Universidade Federal Rural de Pernambuco, Recife, PE, 2003.

VERAS, G.C.; SALARO, A.L.; ZUANON, J.A.S. et al. Growth performance and body composition of giant trahira fingerlings fed diets with different protein and energy levels. Pesq. Agropec. Bras., v.45, p.1021-1027, 2010.

VIAPLANA-MARÍN, I.; FERNÁNDEZ-BORRÁS, J.; BLASCO, J. Effects of the protein/carbohydrate ratio of extruded diets on protein synthesis, protein growth and body composition in juvenile brown trout (Salmo trutta). Aquaculture Intern., v.14, p. 337-353, 2006. 